\title{
Pseudo myocardial infarction due to postoperative ileus
}

\author{
Annick Judenherc Haouzi (i) , ${ }^{1}$ Mary Connolly, ${ }^{2}$ Olivia Zucaro ${ }^{2}$
}

${ }^{1}$ Heart and Vascular Institute, Penn State Milton S Hershey Medical Center, Hershey, Pennsylvania, USA

${ }^{2}$ Division of Internal Medicine, Penn State College of Medicine, Hershey, Pennsylvania, USA

\section{Correspondence to}

Dr Annick Judenherc Haouzi; ahaouzi@pennstatehealth. psu.edu

Accepted 30 November 2021

\section{Check for updates}

(c) BMJ Publishing Group Limited 2021. No commercial re-use. See rights and permissions. Published by BMJ.

To cite: Judenherc Haouzi A, Connolly M, Zucaro O. BMJ

Case Rep 2021;14:e247075. doi:10.1136/bcr-2021-

247075

\section{DESCRIPTION}

An abnormal ECG triggered a cardiology consultation in a 65 -year-old woman with postoperative ileus, a week after a complex abdominal wall reconstruction for recurrent incarcerated incisional hernia. She had no history of cardiovascular disease or risk factors. She presented with abdominal pain, emesis, diaphoresis and tachycardia at $115 / \mathrm{min}$. Blood pressure was 141/74 mm Hg. Physical examination was benign, except for diffuse abdominal distension and tenderness. Basic metabolic panel and complete blood count were unremarkable and serial troponin $\mathrm{T}$ remained undetectable. So was postoperative troponin a week earlier, performed due to transient hypotension.

The ECG showed Q waves in precordial leads (V3-V6), inferior leads, and tall R waves in V1V2, raising concern for anterior, inferior and posterior infarcts. Of note, if it were not for the left axis deviation, this ECG could also have mimicked dextrocardia (figure 1). There were no associated ST-T changes. No previous ECG was available for comparison. In this postoperative context, tachycardia and mildly decreased oxygen saturation 94\% on room air prompted a CT scan that ruled out pulmonary embolism but confirmed significant colic distension.

The ECG was repeated to make sure that the infarct aspect was not related to inappropriate lead placement; ${ }^{1}$ it was unchanged. The absence of any ST-T shift, combined with normal troponins allowed to exclude an acute coronary syndrome. ${ }^{2-4}$ It was felt that the aspect of pseudo infarct was due to the upward displacement of the diaphragm and the heart by the distended bowels.

The patient was treated with supportive care for partial small bowel obstruction, that is, was kept nil by mouth and a nasogastric tube was placed.

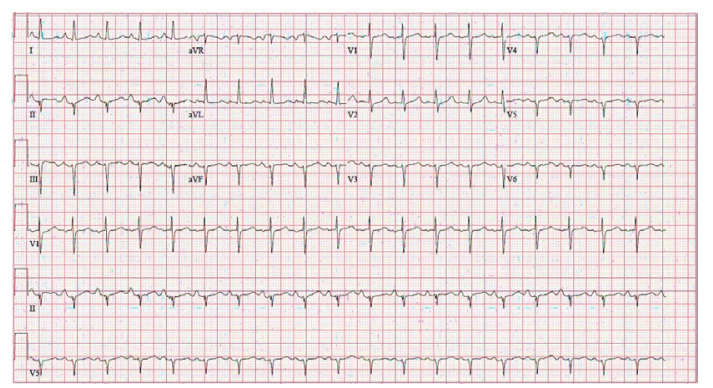

Figure 1 Admission ECG, during ileus: sinus tachycardia, left axis deviation and pseudo infarct in the anterior ( $Q$ waves in V3-6) and inferior ( $Q$ waves in DIIDIII-aVF) territories, as well as in the posterior territory (tall $\mathrm{R}$ waves in $\mathrm{V} 1 \mathrm{~V} 2$ ).

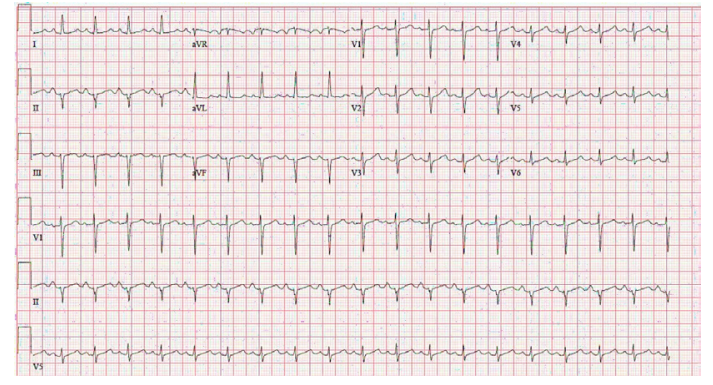

Figure 2 ECG 2 days later, abdominal distension resolving: reappearance of $\mathrm{R}$ waves in precordial leads.

Symptoms settled within 48 hours and the repeat ECG showed reappeareance of $\mathrm{R}$ waves in the precordial leads (figure 2), confirming the diagnosis of pseudo infarct, merely due to cardiac axis horizontalisation. Left axis was still present, either due to residual abdominal distension, or pre-existing axis modification and in this case, meaning either old inferior infarct or isolated benign axis variation. ${ }^{5}$ The patient was discharged home a few days later, and follow-up ECG recommended due to potential clinical significance in case of left axis persistence. $^{6}$

Older patients have a higher risk of early perioperative myocardial infarction after non-cardiac surgery. ${ }^{47}$ However, ECG abnormalities may occur for different reasons than atherosclerotic coronary disease, such as pericarditis, stress cardiomyopathy, vasospastic angina or non-cardiac causes, including alteration of the heart position due to external compression. $^{8-10}$ Although we suspect ileus-related ECG changes may be frequent, only few publications address this issue. ${ }^{8-10}$ Better described are the ECG changes during the second and third trimesters of pregnancy, where a similar mechanism of upward displacement of the diaphragm can be encountered,

Learning points

- ECG modification mimicking myocardial infarction or pseudo dextrocardia may occur following ileus with significant abdominal distension.

- lleus-induced abdominal distension may be responsible for upward displacement of the diaphragm and the heart with horizontal electrical axis, featuring Q waves in inferior, posterior and even anterior territories. 
resulting in frequent left axis deviation with $\mathrm{Q}$ waves in inferior leads and sometimes in V4-V6. ${ }^{11} 12$

Likewise, an ileus-related abdominal distension may lead to ECG axis modification, mimicking myocardial infarct. A proper diagnosis may avoid unnecessary invasive testing.

Twitter Mary Connolly @mmconnolly1

Contributors AJH drafted the manuscript, and selected the figures and references. $\mathrm{MC}$ and $\mathrm{OZ}$ edited the manuscript and researched some of the references.

Funding The authors have not declared a specific grant for this research from any funding agency in the public, commercial or not-for-profit sectors.

Competing interests None declared.

Patient consent for publication Consent obtained directly from patient(s)

Provenance and peer review Not commissioned; externally peer reviewed.

Case reports provide a valuable learning resource for the scientific community and can indicate areas of interest for future research. They should not be used in isolation to guide treatment choices or public health policy.

ORCID iD

Annick Judenherc Haouzi http://orcid.org/0000-0001-5279-5309

\section{REFERENCES}

1 Marafioti V, Variola A. Pseudoinfarction pattern by misplacement of electrocardiographic precordial leads. Am J Emerg Med 2004;22:62-3.
2 Thygesen K, Alpert JS, Jaffe AS, et al. Fourth universal definition of myocardial infarction (2018). Circulation 2018;138:e618-51.

3 Beattie WS, Lalu M, Bocock M, et al. Systematic review and consensus definitions for the standardized endpoints in perioperative medicine (step) initiative: cardiovascular outcomes. Br J Anaesth 2021;126:56-66.

4 , Devereaux PJ, Biccard BM, et al, Writing Committee for the VISION Study Investigators. Association of postoperative high-sensitivity troponin levels with myocardial injury and 30-day mortality among patients undergoing noncardiac surgery. JAMA 2017;317:1642-51.

5 Surawicz B, Knilans T. Chapter 6 - Other Intraventricular Conduction Disturbances. In: Chou's Electrocardiography in Clinical Practice. 6th Edition. Saunders, 2008: 108-23.

6 Seko Y, Kato T, Yamaji Y, et al. Clinical impact of left and right axis deviations with narrow QRS complex on 3-year outcomes in a hospital-based population in Japan. Sci Rep 2021;11.

7 Ollila A, Vikatmaa L, Virolainen J, et al. Perioperative myocardial infarction in non-cardiac surgery patients: a prospective observational study. Scand I Surg 2017;106:180-6

8 Frais MA, Rodgers K, Chest RK. Dramatic electrocardiographic T-wave changes associated with gastric dilatation. Chest 1990;98:489-90.

9 Jawa RS, Easley AR, Anderson DR. Acute ST segment elevation secondary to acute gastric distention. J Cardiol Cases 2013;8:108-12.

10 Herath HMMTB, Thushara Matthias A, Keragala BSDP, et al. Gastric dilatation and intestinal obstruction mimicking acute coronary syndrome with dynamic electrocardiographic changes. BMC Cardiovasc Disord 2016;16:245.

11 Sunitha M, Chandrasekharappa S, Brid SV. Electrocardiographic QRS axis, Q wave and T-wave changes in 2nd and 3rd trimester of normal pregnancy. J Clin Diagn Res 2014;8:17-21.

12 Sumalatha B, Jyotsna M, Indrani G. Electrocardiographic changes during normal pregnancy. Ind J Car Dis Wom 2017;02:035-8.

Copyright 2021 BMJ Publishing Group. All rights reserved. For permission to reuse any of this content visit

https://www.bmj.com/company/products-services/rights-and-licensing/permissions/

BMJ Case Report Fellows may re-use this article for personal use and teaching without any further permission.

Become a Fellow of BMJ Case Reports today and you can

- Submit as many cases as you like

- Enjoy fast sympathetic peer review and rapid publication of accepted articles

Access all the published articles

Re-use any of the published material for personal use and teaching without further permission

Customer Service

If you have any further queries about your subscription, please contact our customer services team on +44 (0) 2071111105 or via email at support@bmj.com.

Visit casereports.bmj.com for more articles like this and to become a Fellow 